\title{
Aircraft Noise Monitoring in Function of Flight Safety and Aircraft Model Determination
}

\author{
Andrija Vidović, ${ }^{1}$ Igor Štimac, ${ }^{2}$ and Robert Zečević-Tadićc ${ }^{3}$ \\ ${ }^{1}$ Department of Air Transport, Faculty of Transport and Traffic Sciences, University of Zagreb, Vukelićeva 4, 10000 Zagreb, Croatia \\ ${ }^{2}$ Zagreb Airport Ltd., Rudolfa Fizira Street 1, p.p. 40, 10150 Zagreb, Croatia \\ ${ }^{3}$ Limitless Airways Ltd., Horvatova 82, 10000 Zagreb, Croatia
}

Correspondence should be addressed to Andrija Vidović; avidovic@fpz.hr

Received 15 July 2016; Revised 27 October 2016; Accepted 30 November 2016; Published 16 January 2017

Academic Editor: Alexandre G. De Barros

Copyright (C) 2017 Andrija Vidović et al. This is an open access article distributed under the Creative Commons Attribution License, which permits unrestricted use, distribution, and reproduction in any medium, provided the original work is properly cited.

\begin{abstract}
This paper presents the research of noise level monitoring at the Zagreb Airport Ltd. The purpose of this paper is to show how the aircraft noise sources can be used as a tool for aircraft detection and for increasing flight safety. The noise measurement was made at the Zagreb Airport by using its professional noise monitoring system. The research has led to new findings, such as determining the aircraft model by measuring the noise level generated by an aircraft during final approach based on its frequency spectrum, as the connectivity from the airport's side to the radar data was unavailable (only ATC). In addition, it is possible to determine the aircraft altitude and, perhaps most significantly, the increase of flight safety through the detection of potential failures on the aircraft structure and/or engine during the overflight of a noise monitoring terminal.
\end{abstract}

\section{Introduction}

Environment protection and the reduction of all types of pollution, especially noise and the exhaust emissions, beside the safety, are key priorities of the aviation industry. Air transport is the youngest type of transport, which began to develop rapidly after the Second World War, with the introduction of turbojet engines. The implementation of such engines in aviation resulted in the construction of larger, safer, and faster aircraft. A negative side effect of the high efficiency of the turbojet engines is noise, which has become more frequent and unbearable with the sudden increase of the number of aircraft operations at airports.

Most of researchers are focusing on the influence of air traffic noise and its negative aspect on human health and the environment. Some of the researchers are oriented toward operative measures to reduce the negative effects of noise. Among a set of factors that impact the aircraft noise perception is the number of flights-a number of aircraft noise events. Jagniatinskis et al. [1] analyzed the number of flights' influence on applicability of the usually used environmental noise metrics: equivalent $L_{\mathrm{eq}}$ and maximum $L_{\max }$ sound level for the long-term interval of their observation. Ozkurt et al. [2] analyzed noise impacts of İzmir Adnan Menderes Airport on public health. The research showed that the number of people who are potentially exposed to high noise levels and threatened by several illnesses, such as hypertension and sleep disturbances, is significant in the surrounding area of the airport. The same author [3] used SoundPLAN software for noise modelling to estimate the noise exposure levels both for current flight operations and for future capacities at the example of Ankara Esenboğa Airport. Bentes et al. [4] analyzed airport noise exposure around Viracopos International Airport by quantifying the proportion of people exposed to the noise in surrounding zones using simulations, integrated noise models, and geographic information systems. Integrated noise model (INM) was used [5] for estimation of the noise impact produced by the airport and for the evaluation of exposed population. The paper [5] presents the utility of AIS (Automatic Identification System) data used to draw up the noise abatement measures in order to reduce the noise impact on population and allow the airport development. Kroesen et al. [6] analyzed the effects of the aircraft noise on residential satisfaction and their study showed that the most important 
determinants of residential satisfaction are road traffic noise annoyance and age and neighbor noise annoyance. Zachary et al. [7] described a multi-indicator assessment and minimization problem focused on the aviation community noise.

In order to determine the most influential factors for the introduction of the noise abatement measures in airport surroundings, Ganic et al. [8] examined 248 European airports. By analyzing the correlation of specific characteristics related to airports (number of runways and aircraft movements, distance from the city and the population of the city that it serves, and gross domestic product (GDP) per capita) and the number of introduced noise abatement measures, the authors proposed the most effective noise abatement measures. A nonhomogeneous Poisson model was used to study the behavior of airport noise levels. The model was used to count the number of times that the noise level exceeds a given threshold in a time interval of interest [9]. Asensio et al. [10] analyzed airport noise insulation programs for reducing the amount of noise to which people are exposed without impacting the operating capacity of an airport. In the papers $[11,12]$ a complete strategic noise mapping research and action noise plans assessment and evaluation are presented with the aim of assessing land use management as an effective tool for protection from aircraft noise. Prats et al. [13] presented the optimization of aircraft noise abatement procedures by using a multiobjective optimization strategy that employs goal, lexicographicegalitarian, and hierarchical optimization techniques.

Sanchez-Perez et al. [14] introduced a new model for aircraft class recognition based on take-off noise signal segmentation and the paper [15] presents an adaptive noise cancelling (ANC) and time-frequency application for railway wheel flat and rail surface defect detection. These papers are the only ones using noise parameters for detecting types of airplanes or detection of possible failures in a vehicle structure.

The negative noise effect on the airport users, airport staff, and the population living in its immediate vicinity is reflected in a form of increased fatigue, exhaustion, anxiety, and a series of other types of mood changes. Although there is always a word about the negative aircraft noise effects, this research showed that the aircraft noise can be used as a tool to achieve the following objectives:

(i) Aircraft model determination, without the radar, based on the aircraft noise and wide frequency spectrums (from $16 \mathrm{~Hz}$ to $16 \mathrm{kHz}$ and more) during the overflight of a noise monitoring terminal [16]: this represents an additional financial and operational benefit, especially for smaller airports with noise monitoring systems that are not connected with the air traffic control radar, and it is necessary for on-time aircraft model determination to make a correlation between the aircraft and the measured noise level.

(ii) Determination of the aircraft altitude by noise levels, which would result in an active monitoring of the altitude during final approach and/or the outbound and its compliance with the defined paths and approach angle. With this indicator, an airport can monitor the aircraft position if it goes below or above the ideal path during its final approach, depending on an idle glide path which is $3^{\circ}$. Following that information, the airport can determine the aircraft trajectory just via the noise monitoring system and without the radar data, as well as determining if the aircraft position is lower than it should be and that the population's complaints related to the noise level are justified.

(iii) The increase of flight safety through the detection of potential failures on the aircraft structure and/or engine based on the noise monitoring measures: during the approach, an engine and aircraft structure correctness check can be performed based on the measured noise level data; that is, possible anomalies can be checked against the frequency spectrum.

With the noise monitoring station located $3,5 \mathrm{~km}$ in front of the runway threshold 05 , the altitude of aircraft can be determined by measuring emission of a noise level during the final approach, and thus one can determine if the aircraft is lower than the optimum angle of the approach path (thus producing higher noise on the ground) or higher. With that method, an airport can easily analyze the complaints from the population living below the approach path without any support of ATC.

What is new in this paper, that is, what sets it apart from the majority of the above-mentioned ones, is that the noise, which is already an inevitable byproduct of traffic processes, can be used for positive purposes presented in the introduction part of this paper.

\section{Methodology}

By joining the EU on the 1st of July 2013, Croatia and its capital city Zagreb with the main international airport in the country and the highest number of annual aircraft movements represent the largest segment in the law adjustment process [17]. Also, after the construction of the new passenger terminal building at the Zagreb Airport Ltd., a high increase in the number of annual aircraft movements is expected. Therefore, it is necessary to continue with all operations regarding the noise level monitoring process. The first purpose of this paper was the noise level monitoring and the adoption of measures necessary for reducing the negative impact of the noise level at the Zagreb Airport Ltd. and the surrounding population. However, the research has led to new findings as shown in the fourth section of this paper. From methodological perspective measuring method and field research, comparison method, analysis method, and description method were used.

2.1. Noise Monitoring Terminals. The currently installed noise monitoring system at Zagreb Airport Ltd. called NoiseDesk consists of four noise monitoring terminals (NMTs, i.e., Noise Monitoring Terminal Plus, Type 3639-E) as shown in Figure 1 [17].

All the four noise monitoring terminals that were bought by Zagreb Airport are of Type 3639-E and they came together with specialized noise monitoring software called ENM (Environmental Noise Model) [18]. To prevent going to each station separately for the purpose of setting, calibrating, and controlling it, each NMT is controlled by this software remotely. Each of the NMTs installed at the Zagreb Airport 


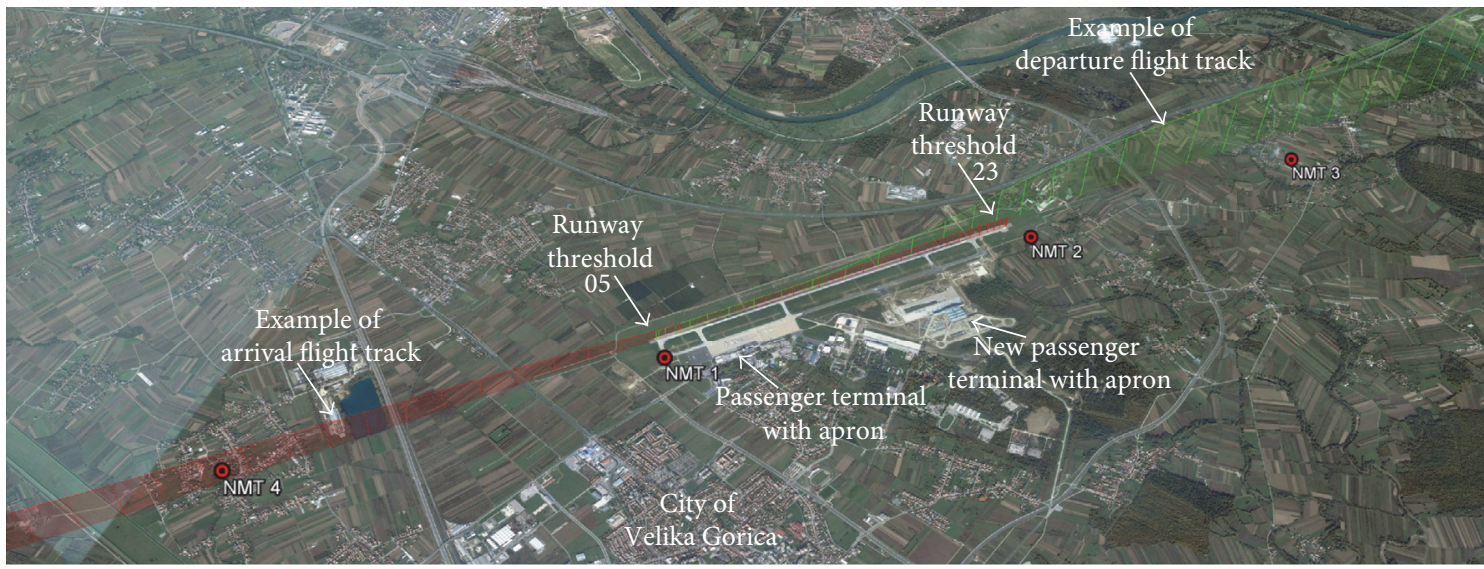

FIgURE 1: Location of the NMTs at Zagreb Airport Ltd.

Ltd. consists of a waterproof shell, base holder, noise level analyzer, microphone unit, and a battery, designed for stable, long-term, continuous outdoor noise level monitoring.

2.2. Noise Level Monitoring at Zagreb Airport Ltd. The currently installed noise monitoring system (NoiseDesk) allows receiving aircraft noise level data in the area of Zagreb Airport Ltd. and its surrounding areas as well, considering the NMT positions. It can also accurately detect every noise exceeding value of each aircraft operation. The system can analyze and report events with a certain noise level and manage certain limitations and permissible noise levels and it can provide all necessary noise level information used for noise mapping.

The four noise monitoring terminals at Zagreb Airport Ltd. (3 fixed and 1 mobile NMTs) operate on the principle of automation, which means that they have a certain trigger set at a certain $\mathrm{dB}$ level which is activated when the noise is higher than the set $\mathrm{dB}$ level value [18]. In case an aircraft produces a noise level greater than the set trigger value, the NMT will save the recorded noise level data into the noise monitoring system. If the aircraft produces a noise level below the set trigger value, the NMT will also record the noise level data but such data will not be further analyzed as it will be characterized as background noise (birds, cars, and wind). The trigger values of each noise monitoring station at the Zagreb Airport Ltd. are set as shown below and can be modified according to the needs of the airport, which is closely related to the distance from the noise source and the NMTs. After measuring noise at potential NMT location, triggers need to be set on those levels where it can clearly distinguish the aircraft noise from the background noise. As each location has its characteristics related to the background noise (houses, industry, sports and infrastructure), different trigger levels were set and those are

(i) NMT 1: trigger value set at $69 \mathrm{~dB}$;

(ii) NMT 2: trigger value set at $67 \mathrm{~dB}$;

(iii) NMT 3: trigger value set at $65 \mathrm{~dB}$;

(iv) NMT 4: trigger value set at $70 \mathrm{~dB}$.
After the process of gathering each noise level monitoring piece of data, the noise monitoring system automatically generates an Excel data table with the following information: date and time of the NMT overflight, record length, runway threshold designator (e.g., 05 or 23 in the Zagreb Airport case), $L_{\text {eq }}$ and $L_{\text {max }}$, sound exposure level (SEL), and effective perceived noise level (EPNL).

Zagreb Airport Ltd. is the main airport in Croatia, which has one runway with the threshold 05-23. Traffic at the airport is a mix of civil and military aircraft. Civil aircraft make above $80 \%$ of ICAO category " $C$ " and the military aircraft mostly consist of MIG-21. From the statistical view, the Zagreb Airport has approx. 39 thousand aircraft movements per year and it is an airport which is open 24/7. Although the opening time is $24 / 7$, all the operations start at/after 6 a.m. and finish by 11 p.m. The configuration of SID (Standard Instrument Departure)/STAR (Standard Terminal Approach Route) procedures is shown in Figure 2.

Taking into consideration that about $90 \%$ of all the takeoffs and landings at Zagreb Airport Ltd. are done from/on the runway threshold 05 [17] and that Airbus A320 model is one of the most frequent aircraft types operating at the Zagreb Airport Ltd., during the research of one week (5th-9th October 2015), 46 aircraft of this model (A320) were observed as they landed on the runway threshold 05 . The measurement results from the period of observation have shown that the meteorological conditions present at that moment in the Zagreb Airport area did not affect significantly the level of the measured noise. The meteorological conditions such as temperature, humidity, pressure, and wind speed can be seen on Figure 3. Figure 4 shows the dominant wind movement in the direction of the position of the Zagreb Airport runway 05-23.

This can be one of the reasons why the frequency graphs have some small changes in values although in general they have the same shape. In addition to that, the pilot's behavior must be the same as it is defined by the procedures of ATC, which means that when the aircraft overflies the NMT, it is already in the ILS glide path, so that any significant deviation can present a safety issue. The pilot's influence on significant noise changes is minimum. Airbus A320 noise level varies in 

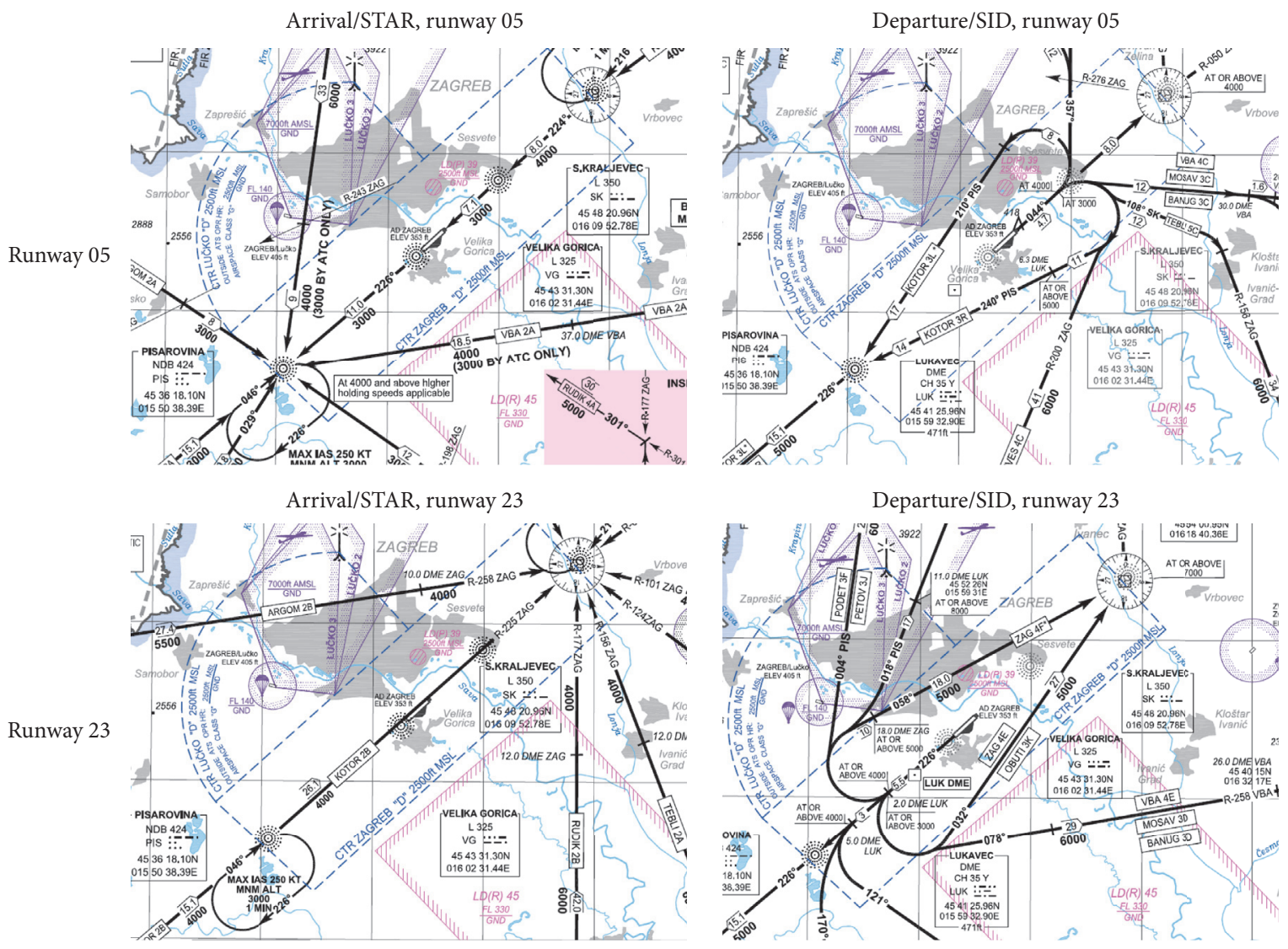

FIGURE 2: Zagreb Airport flight procedures SID/STAR.

relation to the aircraft altitude during NMT4 overflight (i.e., during final approach on runway threshold 05) as shown in Figure 5.

\section{Research Results}

When considering the aircraft noise as one of the major environmental problems of the modern air transport, it is necessary to define and explore its measured values. Although today, in most of the cases, the main concern is the negative impact of aircraft noise, the research carried out by the authors proved that output of measuring and monitoring of the aircraft noise can be used for positive purposes. The main three segments that are especially interesting are shown and described below.

\subsection{Determining the Aircraft Model through the Frequency} Spectrum. One of the main problems of airports which have a noise measuring system not connected to the air traffic control radar is a precise determination of the aircraft model, time of arrival or departure, and the correlation with the measured noise data. The noise monitoring terminals (NMTs) operate on the principle of automation, which means that they have a certain trigger set at a certain $\mathrm{dB}$ level which is activated when the noise is higher than the set $\mathrm{dB}$ level value. Such type of monitoring system is $100 \%$ accurate [18].
The problem occurs at those airports where the airport operating center staff needs to enter manually the landing and take-off times of an aircraft. In the period from 2006 to 2011, one occurrence was recorded at the Zagreb Airport Ltd, when measured noise level was associated with a wrong aircraft model. For example, irregularity happened when the measured noise level of a TU-154 was recorded for one of the general aviation aircraft. The reason behind this is the fact that the landing time from the noise monitoring terminal suited the times manually entered in the airport traffic center. Although sometimes a real difference in the landing times can be only 1 to 2 minutes, the airport traffic center staff do not have the accuracy to equate the times with the times from the noise monitoring terminal.

Due to what has been mentioned before, Zagreb Airport Ltd. has conducted a research with the aim of assigning precisely the measured noise level to a specific aircraft model. During the research, a series number of passing Airbus A320 was monitored and the measured noise levels were analyzed in order to create links to the specific aircraft models. Such approach was unsuccessful because every noise level chart and the overflight of the noise monitoring terminal for the same aircraft model were different (Figure 6) [17]. This was followed by a frequency spectrum monitoring, which showed that there is a uniqueness of each overflight regardless of minor changes in the noise level and their duration. Also, the 

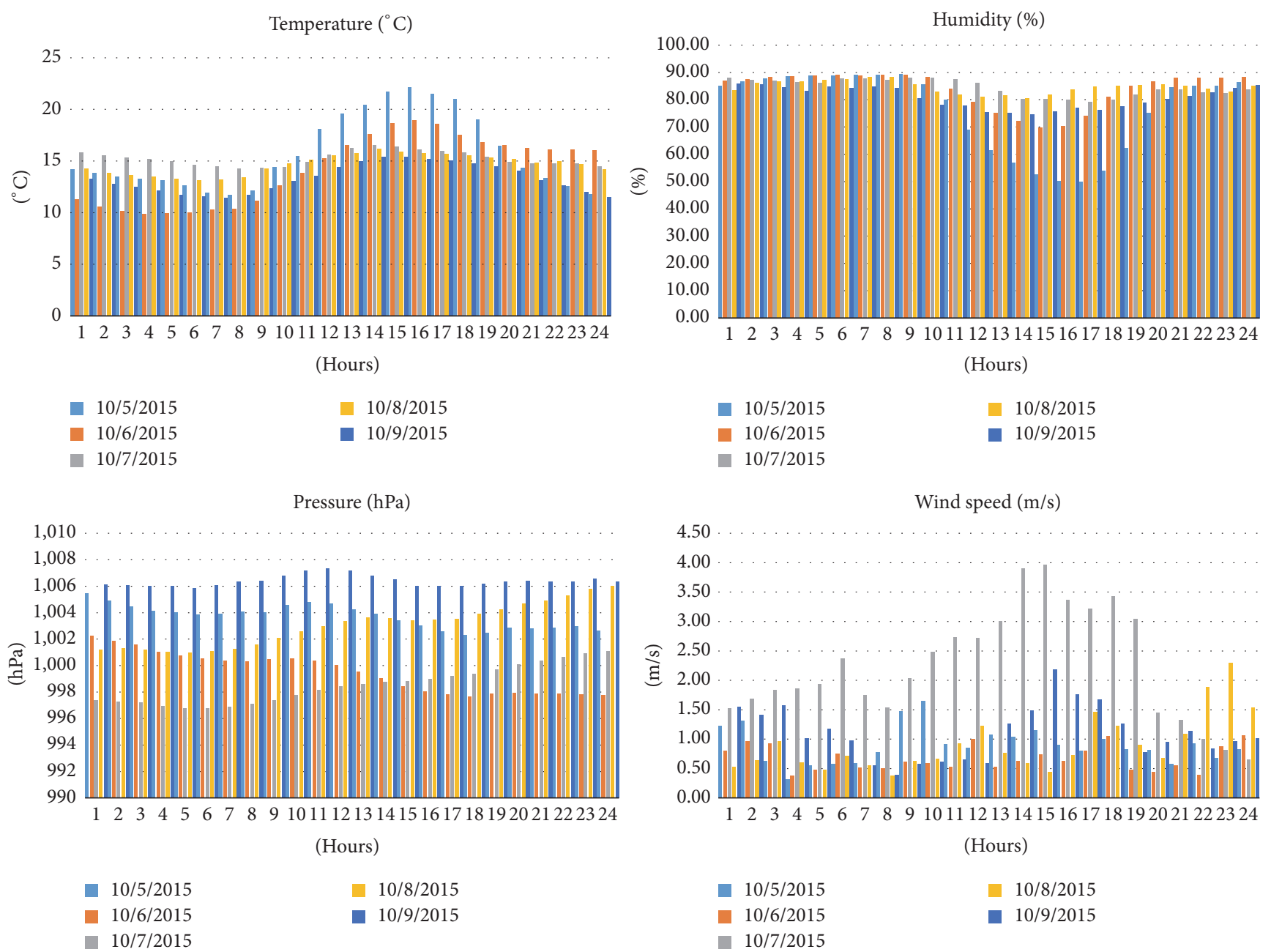

FIGURE 3: Meteorological conditions during the noise measurement from 5th to 9th October 2015.

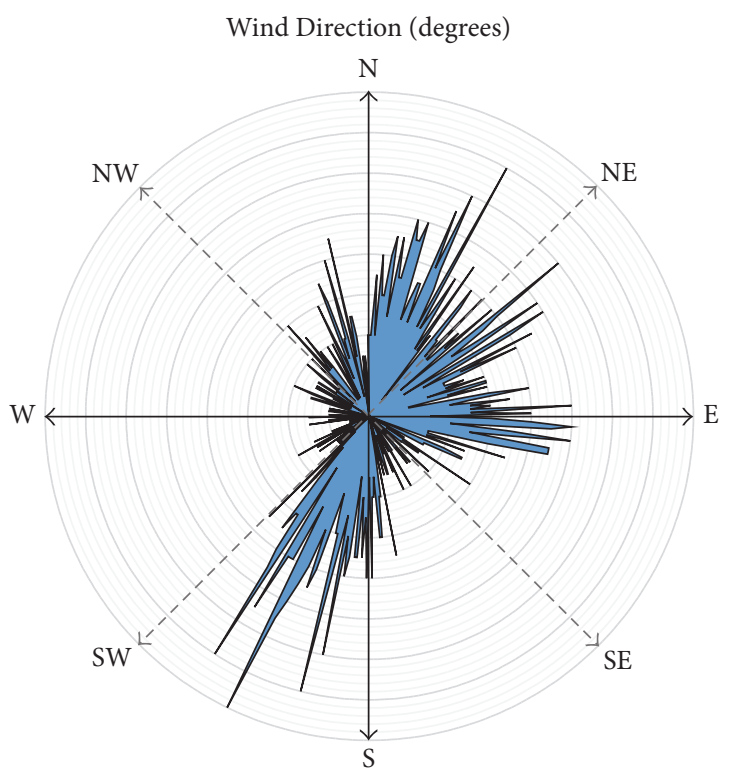

FIGURE 4: The wind direction during the noise measurement from 5th to 9th October 2015. frequency spectrum for each overflight of an Airbus A320 was almost identical, which actually results in its characteristic "fingerprint." In order to confirm these research results, additional measurements and analyses were made for other three aircraft models: Boeing 737, Dash8-Q400, and ATR-42 as shown in Figure 7 [16].

Additional measuring was done to confirm that the fingerprint is the same, and each time when the aircraft A320 overflew the NMT4 the frequency specter graph was mostly the same (with the exact characteristic which other aircraft models do not have). Analyzing other aircraft types, such as B737, Dash8, ATR42, and EMB-120, it was clearly seen that each aircraft type had its own frequency graph characteristics, which can be seen in Figure 7. The conclusion from the research was that there is a connection between the noise (the frequencies) and an aircraft type. Following these results, it was shown that each of these aircraft models had its own characteristic "fingerprint" of the frequency spectrum, and these were in fact their signatures. Based on those results, an insight into matching the correct aircraft model with its own created noise level can be made. 


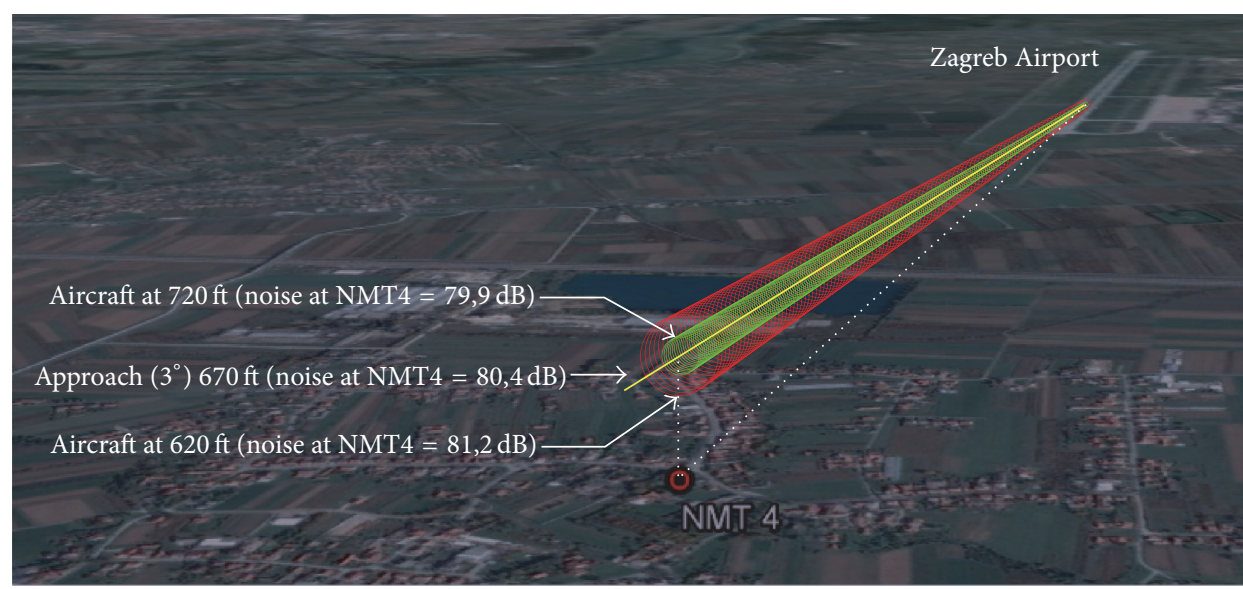

FIGURE 5: A320 noise level variation in relation to the aircraft altitude during NMT4 overflight in village Donja Lomnica.
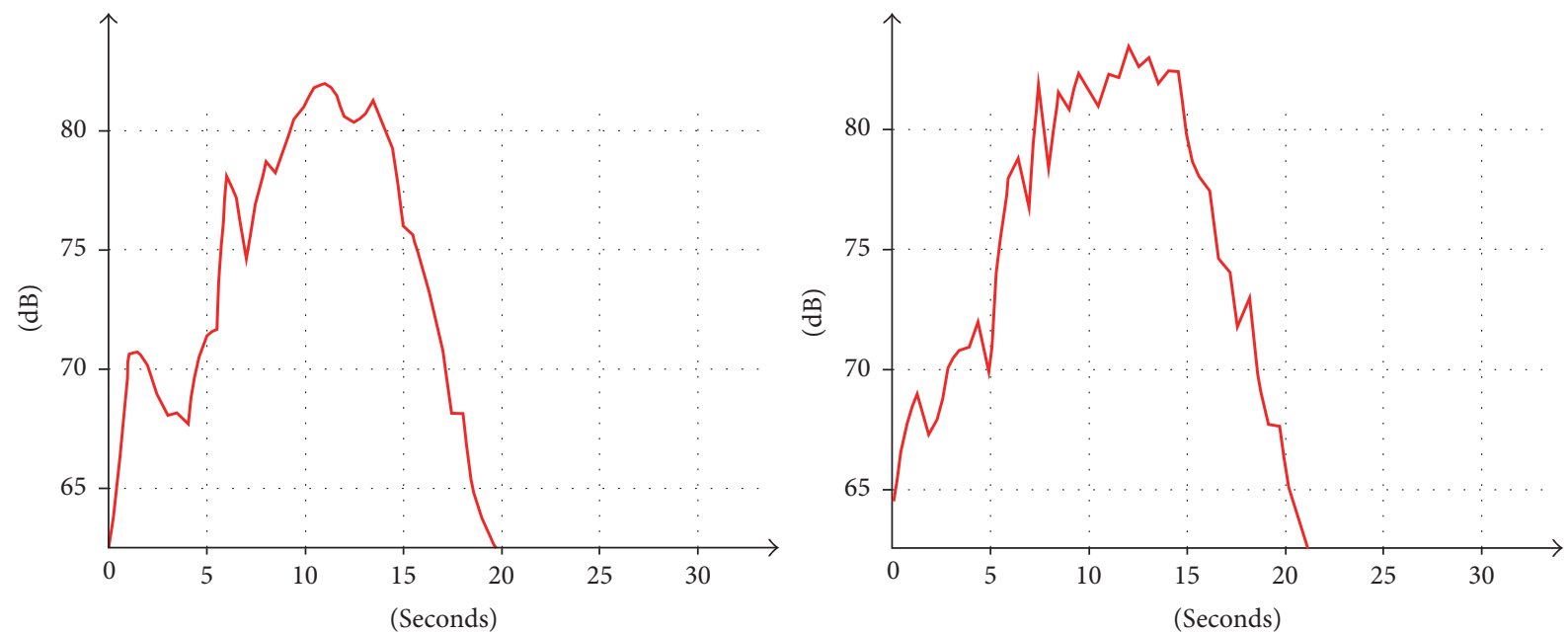

FIGURE 6: Airbus A320 measured noise level values during NMT overflight.

3.2. Determining the Aircraft Altitude through the Noise Level. For the determination of the flight altitude by using the measured noise level produced by a specific aircraft model, 46 aircraft of Airbus A320 model were observed on the NMTs at the Zagreb Airport Ltd during their landing on runway 05. This aircraft model was observed as it was the dominant aircraft on Zagreb Airport during the measuring period (47\% of all the Zagreb Airport operations). The noise monitoring terminal 4 (NMT 4) shown in Figure 1 [17], which measured the noise level, was set up in the village of Donja Lomnica, located directly on the approach path at Zagreb Airport Ltd. The average $L_{\max }$ noise level value during overflight of the NMT 4 at an altitude of $205 \mathrm{~m}( \pm 15 \mathrm{~m})$, that is, $670( \pm 50) \mathrm{ft}$, is $L_{\max }=80.4 \mathrm{~dB}$. Using the formula for the distribution of the sound in space [19] which is presented below, 46 aircraft altitudes were calculated. The results of the calculations are shown in Figure 8. It can be concluded that, out of all 46 aircraft overflights, 29 of them were within the ideal approach of about $3^{\circ}, 4$ aircraft were below the ideal approach with the result of creating higher noise on the ground. Thirteen of them were flying above the ideal approach with the result of creating less noise on the ground but a possible improper approach. In order to check the calculated data, the altitudes were compared with the data of the Croatian Air Traffic Control. The results were confirmed with minor deviations from 5 to maximum 10 meters (possibly due to certain meteorological conditions that were not taken into consideration).

$$
\Delta L=20 \log \left(\frac{h_{1}}{h_{2}}\right),
$$

followed by

$$
h_{2}=\frac{h_{1}}{10_{20}^{\Delta L}},
$$

where

(i) $\Delta L$ stands for the noise correction in accordance with the reference level of noise,

(ii) $h_{1}$ stands for the referent altitude,

(iii) $h_{2}$ stands for the aircraft altitude in relation to the measured level of noise at a noise monitoring terminal. 


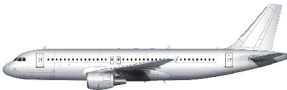

Aircraft model: Airbus A320, AC1

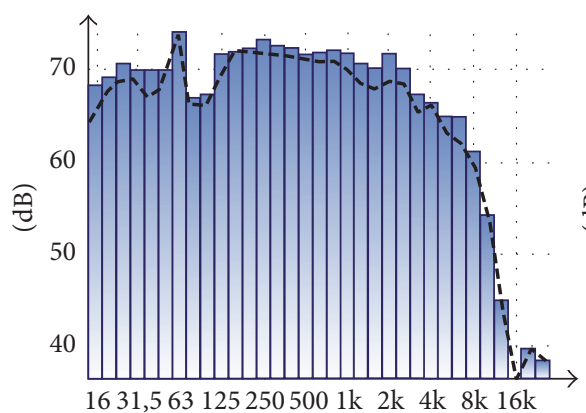

$(\mathrm{Hz})$

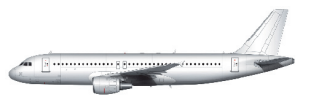

Aircraft model: Airbus A320, AC4

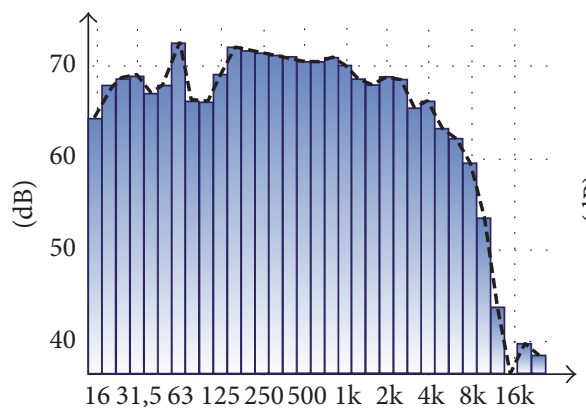

$(\mathrm{Hz})$

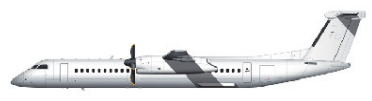

Aircraft model: Dash8-Q400

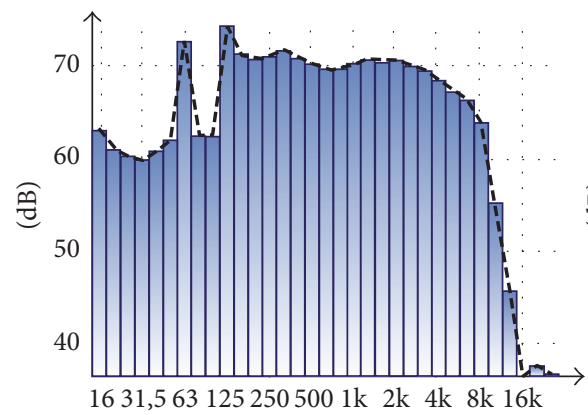

$(\mathrm{Hz})$

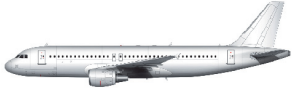

Aircraft model: Airbus A320, AC2

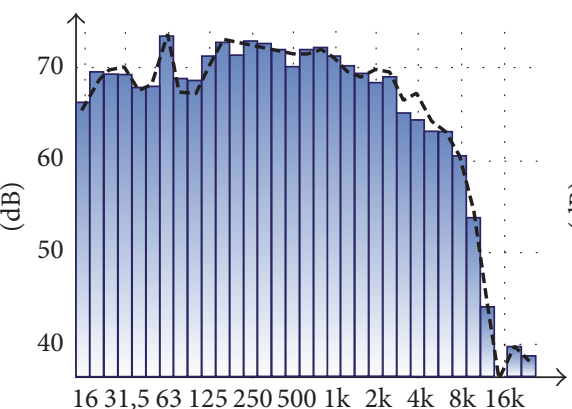

$(\mathrm{Hz})$

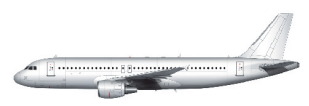

Aircraft model: Airbus A320, AC5

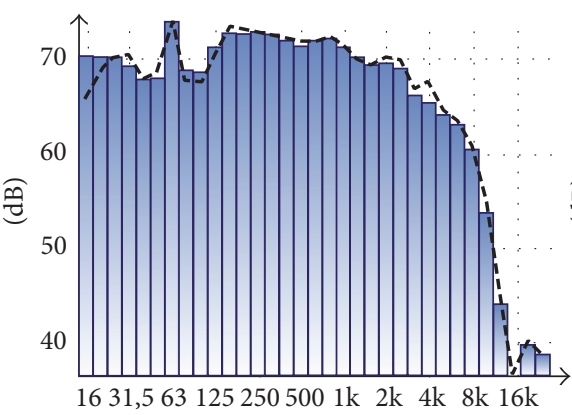

$(\mathrm{Hz})$

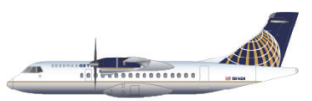

Aircraft model: ATR-42

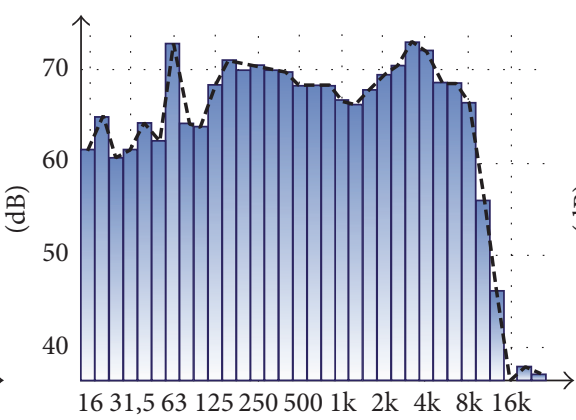

$(\mathrm{Hz})$

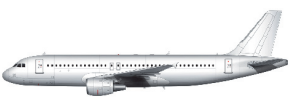

Aircraft model: Airbus A320, AC3

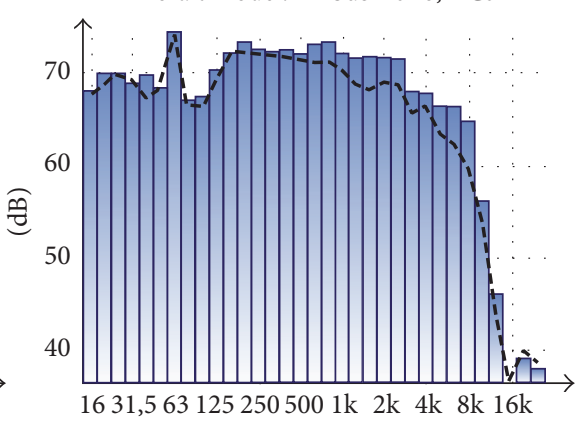

$(\mathrm{Hz})$

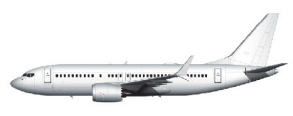

Aircraft model: Boeing 737

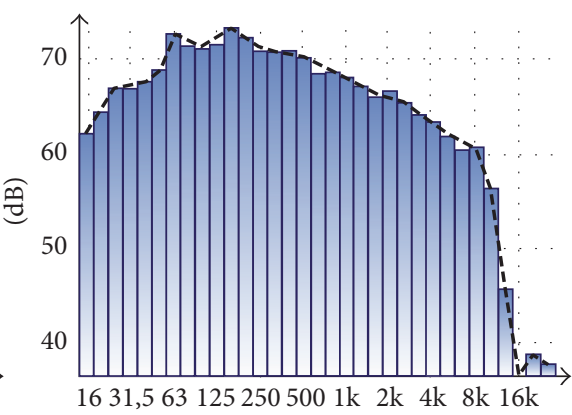

$(\mathrm{Hz})$

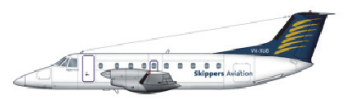

Aircraft model: EMB-120

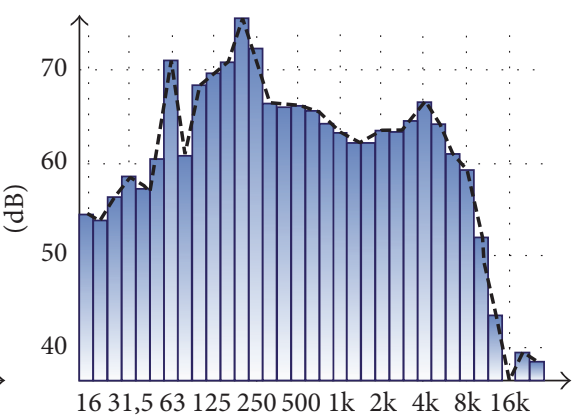

$(\mathrm{Hz})$

Figure 7: The frequency spectrum of Airbus A320, Boeing B737, Dash8-Q400, ATR-42, and EMB-120.

3.3. The Possibility of Detection of Potential Failures on the Aircraft Structure and Aircraft Engine. With an additional analysis of the frequency spectrum of Airbus A320 during all 46 NMT 4 overflights, an average value of all the recorded noise and frequencies from the overflights was made. By collecting those average values, especially from the frequency, the aim was to create average frequency levels from the "right" aircraft so that each flight with anomalies and potential problems can be compared with this average frequency line. The standard deviation was used to show the difference ( $\max$ and min from the mean value). The standard deviation is a measure of the dispersion of a set of data from its mean value. 


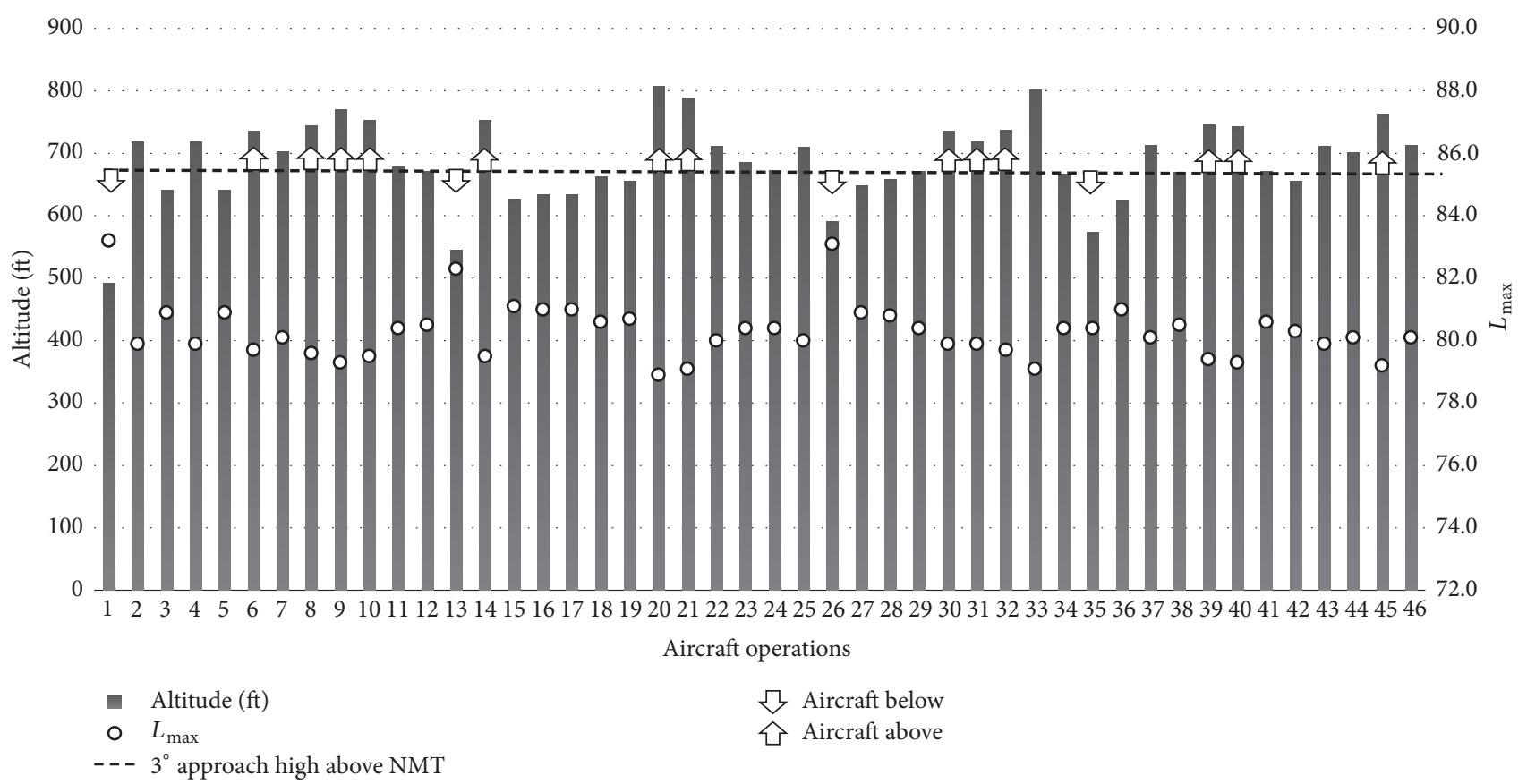

FIGURE 8: A320 altitudes and noise levels during NMT4 overflight.

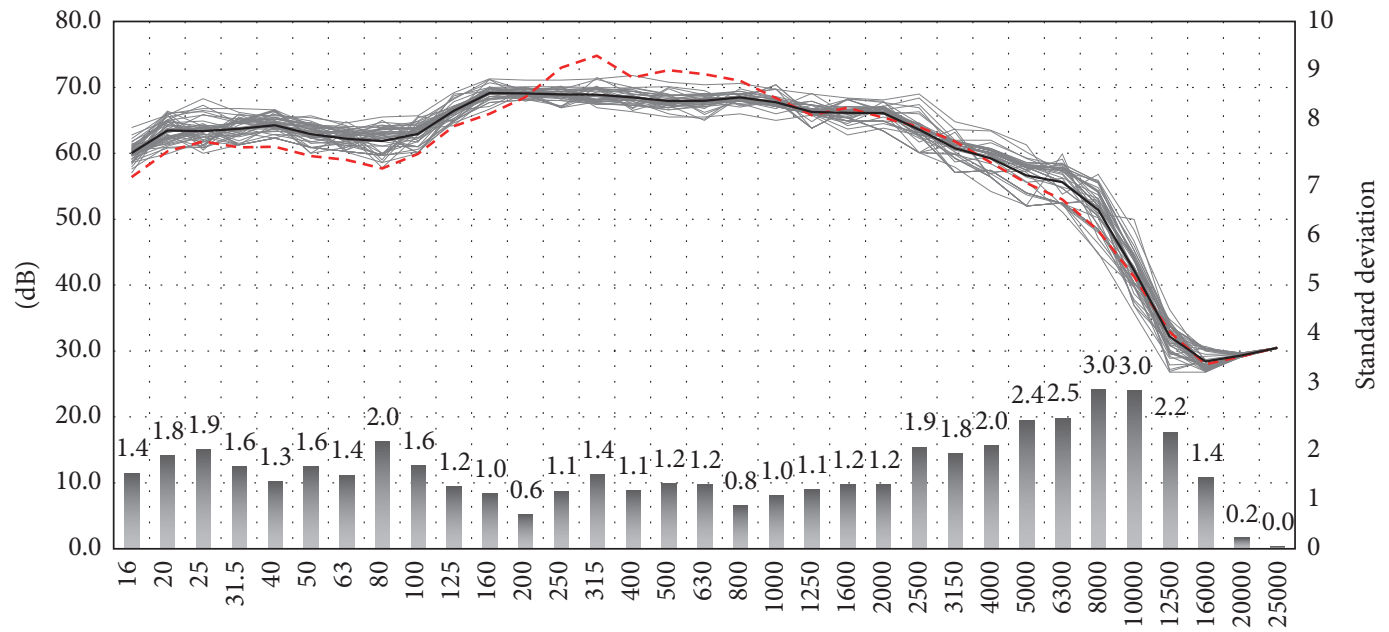

$(\mathrm{Hz})$

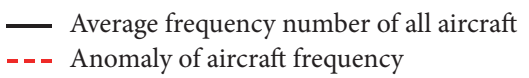

Aircraft frequencies
Standard deviation

FIGURE 9: One significant deviation (anomaly) within the frequency analysis.

In our case, the value of the standard deviation is low (in average 1,5 ), which means that the data points tend to be very close to the mean. Figure 9 [16] shows all line values of each of the listed 46 aircraft through certain frequency bands. One of 46 aircraft had a significant deviation within the frequency values. This particular aircraft had some minor problems, either with the engine or with some of the structure elements of the aircraft, which can form the basis for a further research. The aircraft, as informed by the airline, had a slight wing damage that was repaired, which could be the main reason for the frequency anomalies.
The second reason for such frequency anomalies could be certain problems with the engine or other parts of the airframe. In Figure 10 [17] some examples of possible problems with the landing gear and irregularities on the aircraft structure are shown, which can cause certain anomalies within the frequency spectrum.

As indicated above, it is possible, through the spectrum and a particular sample of NMT overflights, to define average frequency spectrum for each aircraft model and monitor the flight level of aircraft during the approach. It is well known that, after landing, the pilots make an aircraft visual 

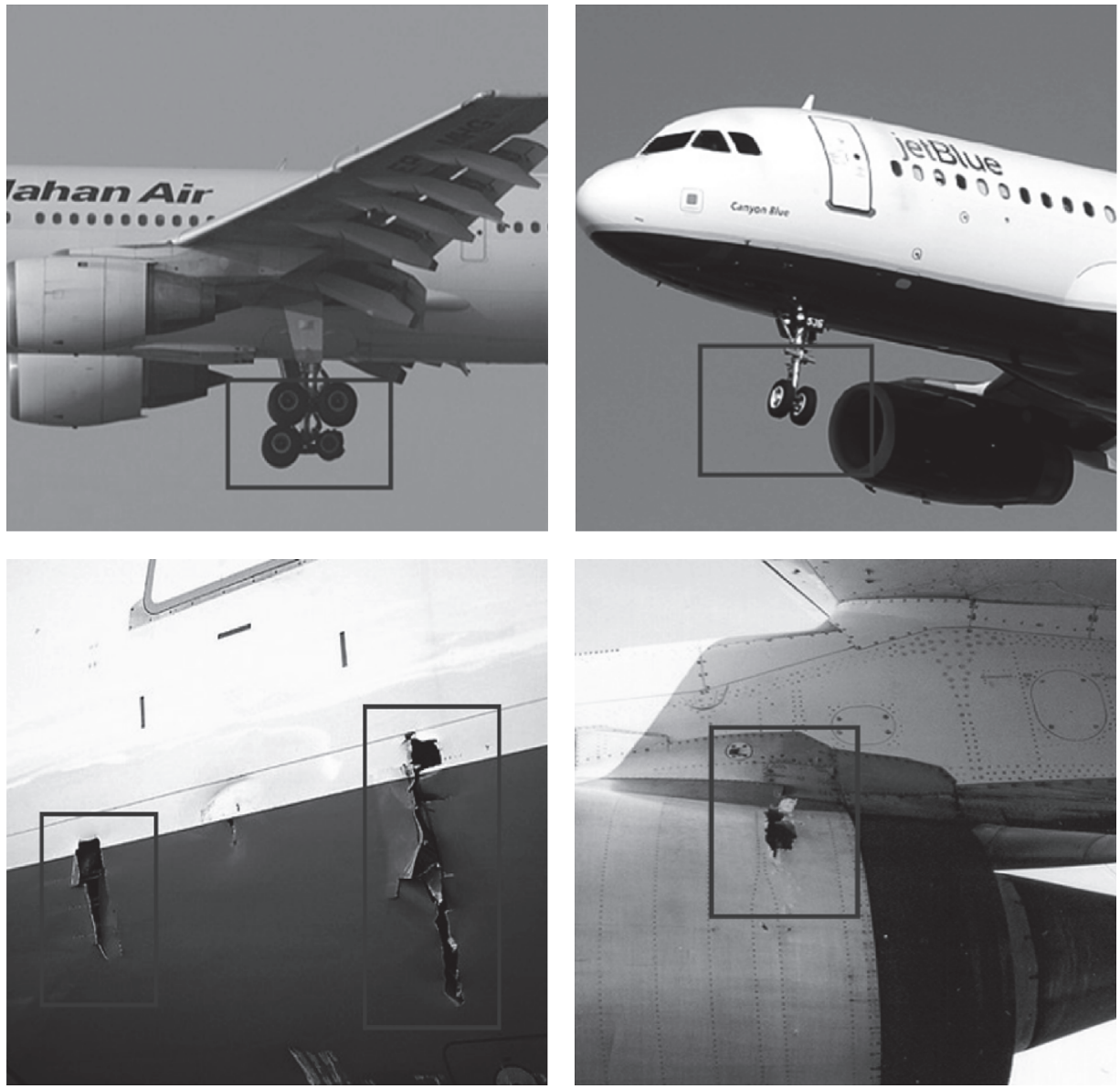

FIGURE 10: Possible aircraft structure problems that can cause anomalies within the frequency spectrum.

inspection to check if the aircraft structure has been damaged. The problem is that the pilots cannot check if the engine or the flaps have some failure since they are not working during this kind of an inspection. With this frequency of airport monitoring and issuing warnings to air carriers of possible problems it would be possible to create "virtual control station/technical maintenance check point" at a certain altitude of the approach path in accordance with the defined angle of approach through which every aircraft has to go anyway. That method cannot substitute a real maintenance check but it can surely increase the level of safety for aircraft operations. The system scheme that was created by the authors by using Google Earth Pro is shown in Figure 11.

\section{Discussion and Conclusion}

Aircraft noise is one of the major environmental problems of modern aviation. A great care of protection is used in all daily operations. The airline industry is aware of its negative impact and adverse effect on humans. In order to protect the local community living in the airport surrounding areas, the measurements of aircraft noise and the analysis of the results are necessary. Due to the social responsibility from the Zagreb Airport, the management implemented the noise monitoring system which is active 24/7. Although at first the

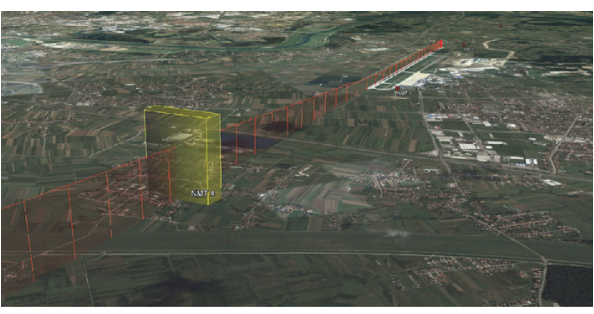

FIGURE 11: Position of the "virtual control station/technical maintenance check point." Source: created by the authors by using Google Earth Pro, 2015.

system was not connected with the radar, it gave significant value information about the noise levels around the airport.

Although in today's society the negative impact of aircraft noise is a major concern and the protection from it is an everyday task, the research carried out by the authors of this paper proved that, by measuring and monitoring of the aircraft noise, it can be used as a tool for achieving several scientific goals by using noise output. The first goal is to determine the aircraft model on the basis of the frequency spectrum. By achieving this goal, many airports (operational centers) can use their noise monitoring stations in order to 
define the exact type when there are several aircraft movements in a short period. The second goal is to determine the aircraft altitude. With this research results, airports can monitor the performance of the airlines for following the ideal glide path line during landing and to send reports to airlines headquarters without the ATC radar and asking for the ATC data. This new noise and aircraft monitoring will increase awareness of the airlines and the pilots about the population and how noise affects them in vicinity of the airport. The third goal was to raise significantly the safety level by using the developed methodology of monitoring the aircraft frequency specter during landing. As the average frequency values were determined from the "right" aircraft type, for example, A320, any anomalies that can be seen from the extremely changing frequency values must be taken seriously into consideration. The source for changing frequencies can be in potential failures in the aircraft structure and/or the aircraft engine during the noise monitoring terminal overflight. With this research as the basis, the safety of flights can be primarily increased, and it is also a good basis for creating a "virtual control station/technical maintenance check point" at a certain distance before the runway in approach, which will control the functionality of aircraft engines, structure, or defining level of its approach. As this research was only focused on landing, the same procedure can probably be used for takeoff. The methodology used by the authors can be a good basis for future research in departure procedures. Additionally, a larger period (whole year) of measuring should be ensured for the future research, with the aim of tracking the noise deviation in different seasons of the year.

This research proves the correlation between the noise frequencies of each aircraft and the determination of aircraft model, and the results of this paper can also be used as the foundation for the development of sound radars for finding aircraft which are not visible on the radar.

\section{Competing Interests}

The authors declare that there is no conflict of interests regarding the publication of this paper.

\section{References}

[1] A. Jagniatinskis, B. Fiks, O. Zaporozhets, and N. van Oosten, "Annual noise assessment in the vicinity of airports with different flights' intensity," Applied Acoustics, vol. 101, pp. 168178, 2016.

[2] N. Ozkurt, S. F. Hamamci, and D. Sari, "Estimation of airport noise impacts on public health. A case study of İzmir Adnan Menderes Airport," Transportation Research Part D: Transport and Environment, vol. 36, pp. 152-159, 2015.

[3] N. Ozkurt, "Current assessment and future projections of noise pollution at Ankara Esenboğa Airport, Turkey," Transportation Research Part D: Transport and Environment, vol. 32, pp. 120128, 2014.

[4] F. M. Bentes, T. A. Heleno, and J. G. Slama, "Analysis of airport noise exposure around Viracopos International Airport using geographic information systems," Journal of Air Transport Management, vol. 31, pp. 15-17, 2013.
[5] G. Licitra, P. Gagliardi, L. Fredianelli, and D. Simonetti, "Noise mitigation action plan of Pisa civil and military airport and its effects on people exposure," Applied Acoustics, vol. 84, pp. 2536, 2014.

[6] M. Kroesen, E. J. E. Molin, H. M. E. Miedema, H. Vos, S. A. Janssen, and B. van Wee, "Estimation of the effects of aircraft noise on residential satisfaction," Transportation Research Part D: Transport and Environment, vol. 15, no. 3, pp. 144-153, 2010.

[7] D. S. Zachary, J. Gervais, and U. Leopold, "Multi-impact optimization to reduce aviation noise and emissions," Transportation Research Part D: Transport and Environment, vol. 15, no. 2, pp. 82-93, 2010.

[8] E. M. Ganic, F. Netjasov, and O. Babic, "Analysis of noise abatement measures on European airports," Applied Acoustics, vol. 92, pp. 115-123, 2015.

[9] C. Guarnaccia, J. Quartieri, C. Tepedino, and E. R. Rodrigues, "An analysis of airport noise data using a non-homogeneous Poisson model with a change-point," Applied Acoustics, vol. 91, pp. 33-39, 2015.

[10] C. Asensio, M. Recuero, and I. Pavón, "Citizens' perception of the efficacy of airport noise insulation programmes in Spain," Applied Acoustics, vol. 84, pp. 107-115, 2014.

[11] K. Vogiatzis, "Airport environmental noise mapping and land use management as an environmental protection action policy tool. The case of the Larnaka International Airport (Cyprus)," Science of the Total Environment, vol. 424, pp. 162-173, 2012.

[12] N. Ozkurt, D. Sari, A. Akdag, M. Kutukoglu, and A. Gurarslan, "Modeling of noise pollution and estimated human exposure around Istanbul Atatürk Airport in Turkey," Science of the Total Environment, vol. 482-483, no. 1, pp. 486-492, 2014.

[13] X. Prats, V. Puig, and J. Quevedo, "A multi-objective optimization strategy for designing aircraft noise abatement procedures. Case study at Girona airport," Transportation Research Part D: Transport and Environment, vol. 16, no. 1, pp. 31-41, 2011.

[14] L. A. Sanchez-Perez, L. P. Sanchez-Fernandez, S. Suarez-Guerra, and M. G. Lopez-Pacheco, "Dynamic hierarchical aggregation of parallel outputs for aircraft take-off noise identification," Engineering Applications of Artificial Intelligence, vol. 46, part A, pp. 33-42, 2015.

[15] B. Liang, S. Iwnicki, A. Ball, and A. Young, "Adaptive noise cancelling and time-frequency techniques for rail surface defect detection," Mechanical Systems and Signal Processing, vol. 54-55, pp. 41-51, 2015.

[16] I. Štimac, A. Vidović, and V. Sorić, "Determination of aircraft model using a noise measuring system," in Proceedings of the 4th International Conference on Transport Science (ICTS 2011), Portorož, Slovenia, 2011.

[17] I. Štimac, Implementacija sustava praćenja i analiza buke na Zračnoj luci Zagreb [M.S. thesis], Faculty of Transport and Traffic Sciences, Zagreb, Croatia, 2009.

[18] Brüel \& Kjær, Technical Documentation, INM Link Version 3, Type 7834, 2003.

[19] O. Zaporozhets, V. Tokarev, and K. Attenborough, "Predicting noise from aircraft operated on the ground," Applied Acoustics, vol. 64, no. 10, pp. 941-953, 2003. 


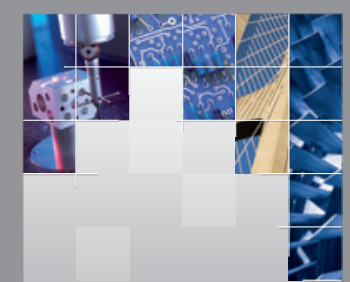

\section{Enfincering}
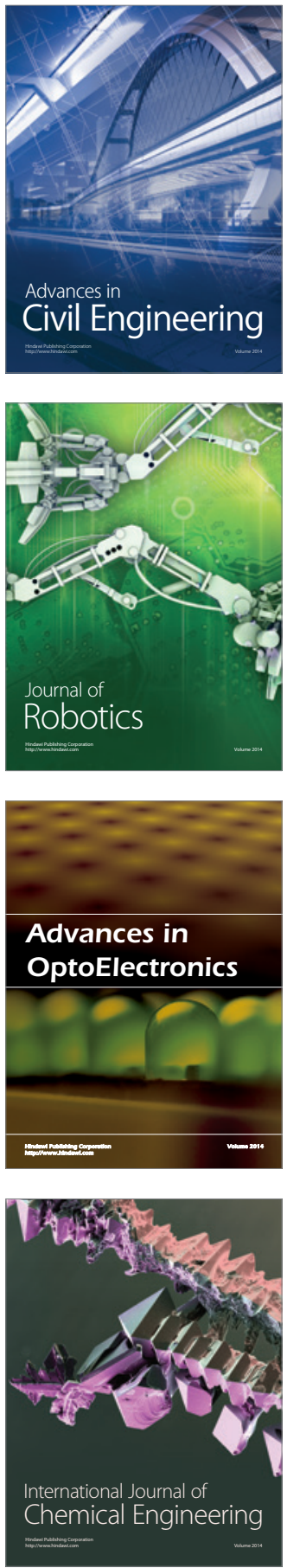

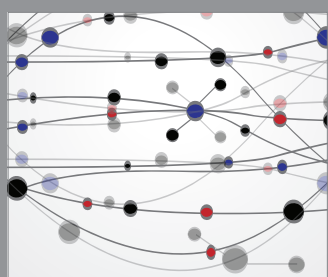

The Scientific World Journal

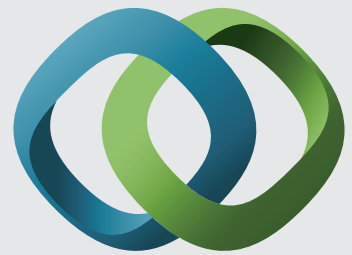

\section{Hindawi}

Submit your manuscripts at

https://www.hindawi.com
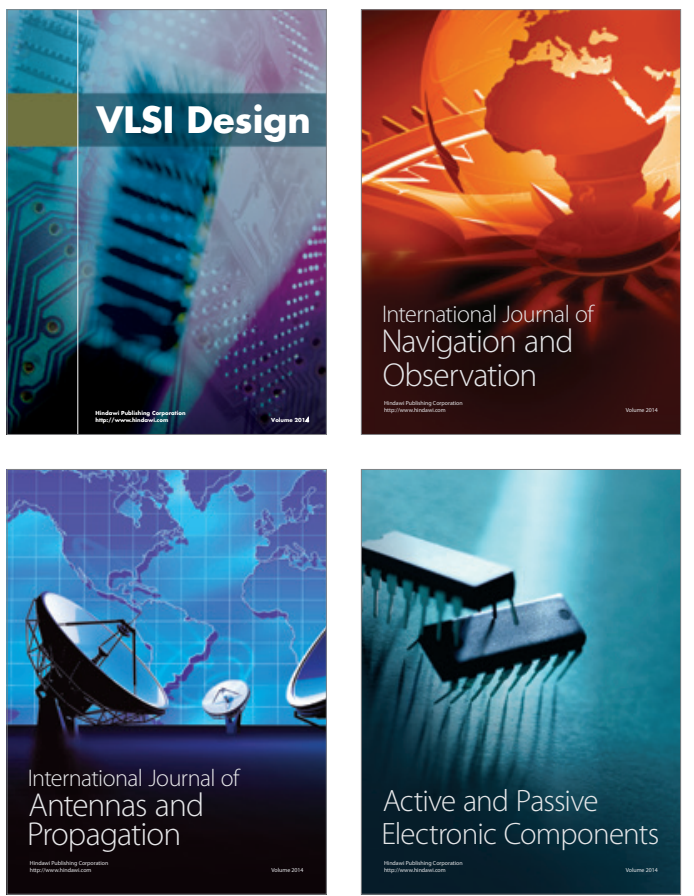
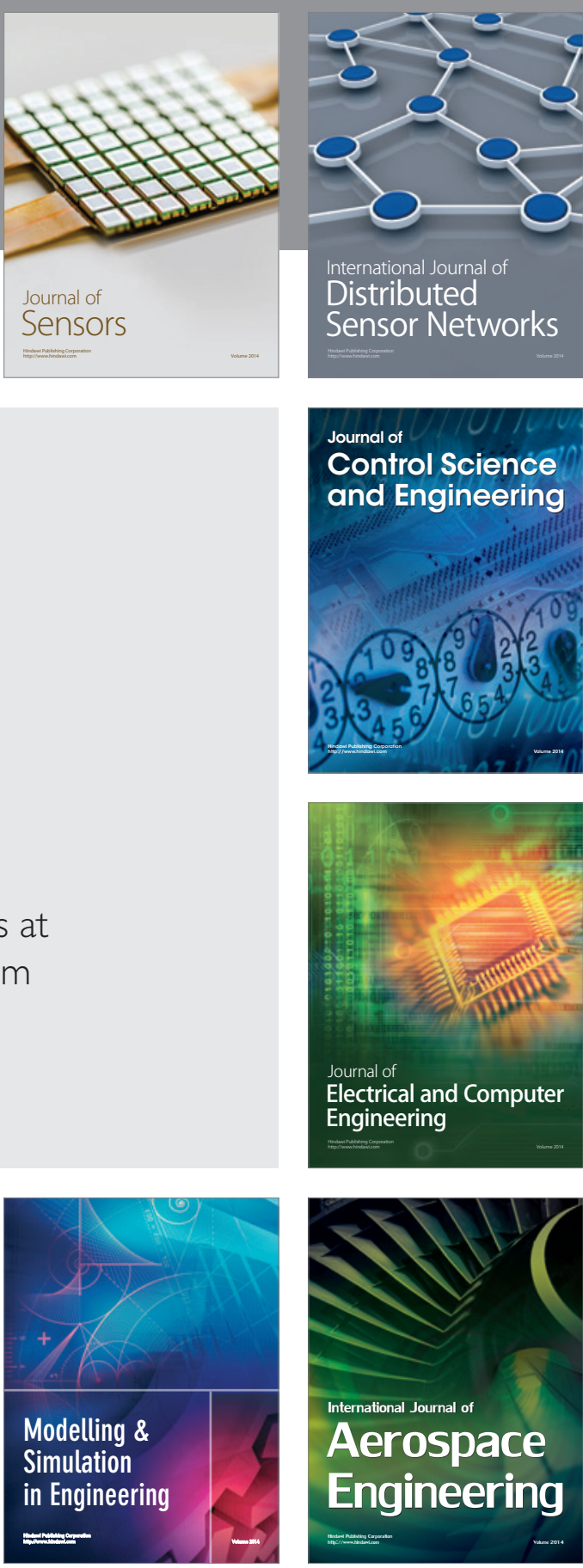

International Journal of

Distributed

Sensor Networks

$-$

Joumal of

Control Science

and Engineering
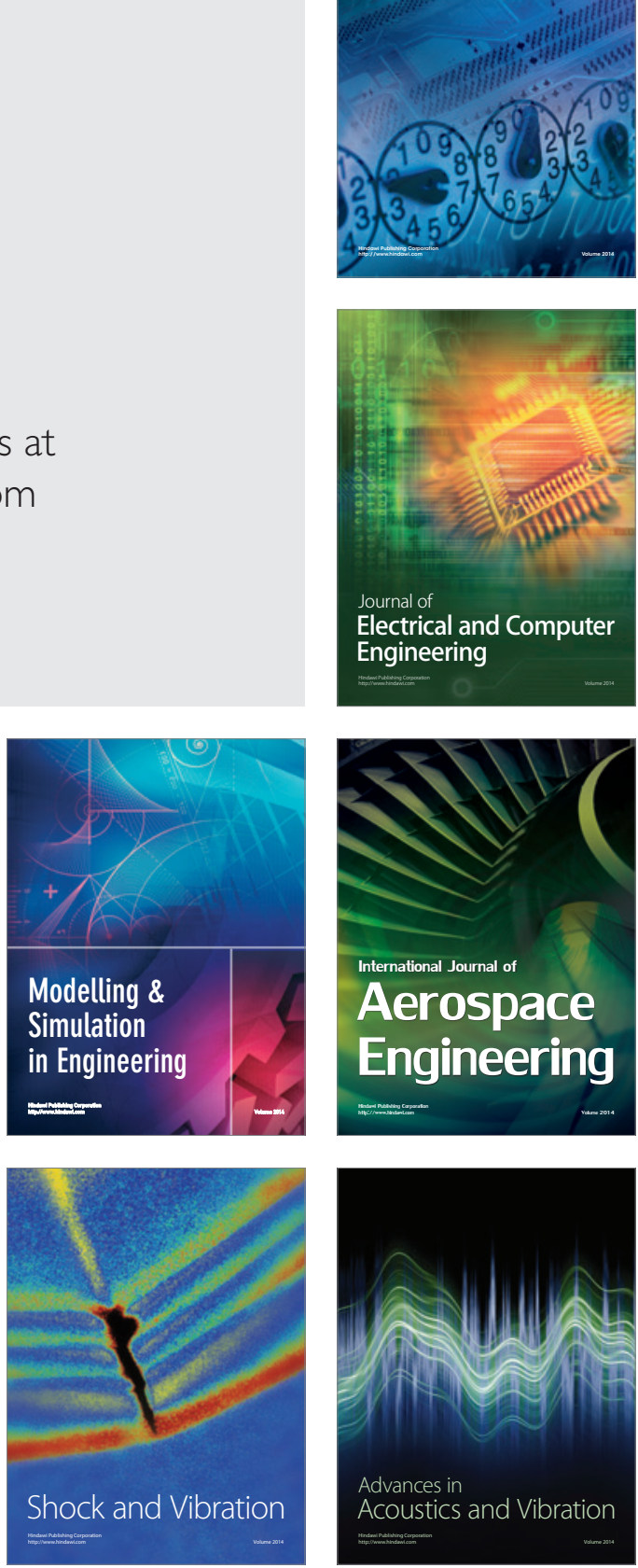